\title{
BRAINSTEM DYSFUNCTION IN SARS-COV-2 INFECTION CAN BE A POTENTIAL CAUSE OF RESPIRATORY DISTRESS
}

\section{(Review article)}

Authors: Calixto Machado, MD, Ph.D.

Joel Gutierrez, MD, Ph.D.

Institute of Neurology and Neurosurgery

Department of Clinical Neurophysioloy

Havana, Cuba

Address: $\quad$ Calixto Machado, MD, Ph.D., FAAN (Corresponding Author)

Institute of Neurology and Neurosurgery Department of Clinical Neurophysiology 29 y D, Vedado

La Habana 10400

Cuba

Email: braind@infomed.sld.cu

Keywords: SARS-CoV-2 (CoV-2); COVID-19; coronavirus; pandemic; respiratory distress; brainstem; respiratory center; 


\begin{abstract}
Covid-19 pandemic has captivated scientists to investigate if this new disease can affect the central nervous system (CNS). The most challenging symptoms of Covid-19 are related to respiratory distress, and most patients admitted in intensive care units cannot breathe by their own. Therefore, a crucial question is if respiratory distress can be partially explained by the CNS affection. SARS-Cov-2 is a beta-coronavirus that shares high similarities with SARS-CoV. The infection of SARS-CoV has been reported in the brains from both patients and experimental animals, where the brainstem was heavily infected. Those coronaviruses have been able to invade the brainstem via a synapseconnected route to the medullary respiratory center, where the infected regions included the nucleus of the solitary tract and nucleus ambiguous. The vagal afferent nerves from receptors in the lung communicate with the medulla and pons respiratory control centers to coordinate inspiration and expiration. This suggests that neuroinvasion of SARS-CoV2 might play a role in the acute respiratory failure of Covid-19. Therefore, acute respiratory distress in Covid-19 can be partially explained by brainstem dysfunction, suggesting the needs of more specific and aggressive treatments with the direct participation of neurologists and neurointensivists.
\end{abstract}




\section{INTRODUCTION}

The world is facing a terrible pandemic of coronavirus infectious disease 2019 (Covid19), ${ }^{1-8}$ caused by SARS-Cov-2, which has captivated scientists to investigate the way that this new disease can affect the central nervous system (CNS). ${ }^{9-16}$ A crucial question is if respiratory distress, commonly found in this pandemic, is at least partially explained by CNS affection.

Respiratory viruses are the leading cause of acute respiratory diseases. Coronaviruses $(\mathrm{CoVs})$ commonly cause enteric and respiratory diseases in animals and humans. ${ }^{10,17,18}$. Human CoVs were responsible of two worldwide outbreaks: the severe acute respiratory syndrome $\mathrm{CoV}$ (SARS-CoV) and the Middle East respiratory syndrome CoV (MERS$\mathrm{CoV}) .{ }^{17,}{ }^{19-21}$ SARS-Cov-2 is a beta-coronavirus that shares similarities with SARS-CoV. So far, it is proposed that it binds by glycoproteins expressed on its surface to the receptor of the angiotensin-converting enzyme 2 (ACE2), which is distributed in the respiratory tract epithelium, the lung parenchyma and other areas such as the gastrointestinal tract, endothelial cells, among others. ${ }^{18,19,22-24}$

Nonetheless, extra-pulmonary symptoms have been described in these viruses, highlighting their capacity to cause neurological complications: febrile seizures, loss of consciousness, convulsion, ataxia, status epilepticus, encephalitis, myelitis, neuritis with several reports in experimental models..$^{9-11,13,19,25-34}$ We have recently reviewed that anosmia and hypogeusia as significant alerting initial or unique symptoms of COVID$19 .^{35}$

Curiously, neurotropic and neuro-invasive capabilities have been described in several of their hosts, including humans among them, leading to symptoms such as multiple sclerosis (MS) and encephalomyelitis. A rising amount of evidence demonstrates that neurotropism is one shared feature of CoVs. The infection of SARS-CoV has been 
reported in the brains from both patients and experimental animals, where the brainstem was heavily infected. Furthermore, some coronaviruses have been demonstrated able to spread via a synapse-connected route to the medullary cardiorespiratory center from the

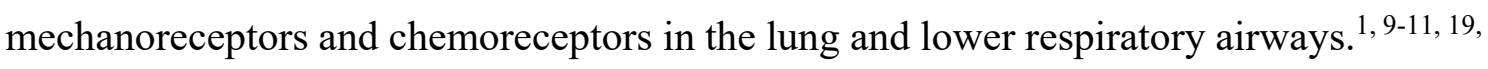
36,37

Most CoVs share a similar viral structure and infection pathway, and therefore the infection mechanisms previously found for other CoVs may also be applicable for SARSCoV-2. Several routes used by neurotropic virus to reach CNS have been described, including transneural and hematogenous pathways. CoV has been described to reach the brain via olfactory bulb, spreading from this point forward into the CNS and the periphery. $1,14,15,21,38-43$

It has been discussed that human coronavirus $(\mathrm{HCoV})$ reaches the CNS through the olfactory bulb, causing inflammation and demyelination. This pathway is an excellent mechanism to access CNS for viruses that enter the body intranasally. Olfactory nerve has the particularity to be in communication with the nasal epithelium and also with the olfactory bulb, the entryway to the CNS. ${ }^{12,44-49}$

Experimental models have demonstrated that ablation of the olfactory nerve limits its neurotropic capacities in mice. As soon as the infection is established, the virus can spread to the whole brain and CSF in less than 7 days. Consequently, it has been reported that this virus can induce demyelination in studies of glial cultures. ${ }^{50,51}$

Therefore, based on previous pandemics, ${ }^{21,52,53}$ medical care should not be limited to the organs whose symptoms are moderately easy to be assess, such as lung, kidney, and liver, because the brain could be lethally affected. The potential neuroinvasion of SARSCoV-2 must prompt physician to be attentive on the commencement of neurological symptoms, to achieve and early diagnostics, and neuroprotection. ${ }^{17,}$ 19, 20 


\section{Neurological symptoms in other viral pandemics}

In 2009 a new H1N1 pandemic was the causative agent of high mortality rates and exhibited increased reports of neurological complications. According to Asadi-Pooya et al., a retrospective study of a sample of 55 patients infected with H1N1 detected a $50 \%$ of visible neurological symptoms. ${ }^{54}$

Several neurological complications have been observed in $\mathrm{CoV}$ epidemics: encephalitis, myelitis, meningitis, seizures, and Guillain-Barre syndrome (Sivadon-Tardy et al., 2009). ${ }^{14,16,36,55-57}$ Seropositivity for coronaviruses has been reported in a variety of neurologic disorders, which include encephalitis, 11 optic neuritis, 12 multiple sclerosis, 13 and Parkinson disease. ${ }^{57} 58,59$ Virus has also been isolated from the CSF and brain of patients with multiple sclerosis.15 Viruses implicated include HCoV-229E, HCoV-293, and HCoV-OC43. ${ }^{57}$

Hung et al. reported the first case of SARS-CoV infection with neurological manifestations in a 59-year-old woman with, in the year. The patient was initially admitted with swinging fever, chills, productive coughing and diarrhea, which eventually lead to oxygen requirements, vomit, seizures and episodes of four-limb twitching. SARS$\mathrm{CoV}$ infection was established in tracheal aspirates and cerebral spinal fluid (CSF) samples. ${ }^{57,60}$

SARS-CoV was isolated from the brain of a patient who had shown neurological deficits on 28th day of infection. This is concordance with previous studies from other coronavirus epidemics, stating that SARS-CoV, invades the CNS. Moreover, autopsies with immunohistochemistry, in situ hybridization, and electron microscopic techniques of brain tissue have confirmed SARS-CoV infection of neurons, showing neuronal degeneration, surrounded by edema. Hence, taking in consideration that both virus are 
taxonomically near identical, SARS-CoV-2 should present a very similar trend to affect the SNC. ${ }^{9,21,57,61}$

\section{Evidence of the COVID-19 Virus Targeting the CNS}

The prognostic and diagnostic significance of neurological sign and symptoms in COVID-19 patients can be gauged by fact that the protocol designed to investigate the First Few X cases (FFX) and their close contacts by the World Health Organization (WHO), includes a separate section for "other neurological signs" in addition to separate columns for respiratory symptoms. ${ }^{33}$ Additionally, reports of COVID-19-affected individuals experiencing convulsions is alarming and need to be distinguished from febrile convulsions, that is expected to occur with high-grade fever in patients with COVID-19.9-11, 19,44

The dissemination of COVID-19 in the systemic circulation or across the cribriform plate of the ethmoid bone during an early or later phase of the infection can lead to brain infection of SARS-CoV. When the of SARS-CoV-2 virus enters the general circulation reaches the cerebral circulation, where the slow movement of the blood within the microcirculation, could be one of the factors that may facilitate the interaction of the SARS-CoV-2 virus spike protein with ACE2 expressed in the capillary endothelium. Subsequent budding of the viral particles from the capillary endothelium and damage to the endothelial lining can favor viral access to the brain. ${ }^{10,17,19,36,62}$

The brain expresses angiotensin converting enzyme 2 (ACE2) receptors that have been detected over glial cells and neurons, which suggest that these cells are potential targets of COVID-19. As can be found in endothelial cells of the brain, this raises the hypothesis that strokes linked with SARS-CoV-2 might be directly associated to the viral infection, and encephalitis could be a probable complication. ${ }^{57,60}$ A recent study of 214 patients 
complaining Covid-19, reported neurological manifestations in COVID-19 in 78 (36.4\%), such as acute cerebrovascular diseases, consciousness impairment and skeletal muscle symptoms, suggesting a neurotropic potential for SARS-CoV-2.${ }^{57} 63$ Other study from Wuhan city of Covid-19 reported neurologic symptoms, such as headache (about 8\%), nausea and vomiting $(1 \%){ }^{64}$

The National Health Commission of China of the Diagnosis and Treatment Guidelines for COVID-19 published human histopathological studies finding edema and partial neuronal degeneration in brain tissues ${ }^{65}$. Other study reported the presence of SARSCoV-2 in the cerebrospinal fluid (CPF) of a Covid-19 patient. $^{60}$

These studies, without a reasonable doubt, validate our rationale of CNS being targeted by SARS-CoV-2, as pointed out recently. ${ }^{57}$

\section{Brainstem dysfunction in SARS-CoV-2 infection as a potential cause of respiratory distress}

It has been argued that almost all the $\beta \mathrm{CoVs}$ are not always limited to the respiratory tract and that they may also invade the CNS, leading to neurological complications. Hence, according to the high likeness between SARS-CoV and SARS-CoV2, it has been suggested that a neuroinvasion of SARS-CoV-2 plays a role in the acute respiratory failure of patients complaining COVID-19. ${ }^{20,44,51}$

SARS-CoV-2 causes acute, highly lethal pneumonia with clinical symptoms similar to those reported for SARS-CoV and MERS-CoV. ${ }^{19,37,61,66}$ Chest computerized tomography (CT) scans in most patients with fever, dry cough, and dyspnea have shown bilateral ground-glass opacities. However, a main difference from SARS-CoV is that and SARS-CoV-2-infected patients infrequently showed prominent upper respiratory tract 
signs and symptoms, suggesting that the target cells of SARS-CoV-2 may be located in the lower airway. ${ }^{67,68}$

The most characteristic and challenging symptoms of Covid-19 are related to a respiratory distress. ${ }^{69-72}$ Wang et al. reported that about $46 \%$ to $65 \%$ of the patients About $46 \%$ to $65 \%$ of the patients admitted in the intensive care unit (ICU) deteriorated in a brief period of time and died because of respiratory failure. According to these data, about $89 \%$ of the patients in ICUs could not breathe by their own in the intensive care, worsening in a short period of time and dying due to respiratory failure. ${ }^{68,73}$

Using transgenic mice it was possible to demonstrate that when SARS-CoV or MERSCOV were given intranasally, these viruses could enter the brain, probably via the olfactory nerves, rapidly spreading to specific brain areas, such as the thalamus and the brainstem. ${ }^{44,57,74}$

Based on clinical observations several authors have considered that the West Nile virus (WNV) presumptively causes lesions in the CNS that harmfully affect pulmonary function. WNV infects and causes lesions in the brain stem of human patients, which contains respiratory control functions in the medulla and pons. Another possible cause of WNV-induced EMG suppression is cytokine signaling of the vagal afferent nerves to central autonomic pathways. ${ }^{75-77}$

It has been widely supported that that lesions in the medulla can cause respiratory dysfunction, like in congenital central hypoventilation syndrome, ${ }^{78}$ or severe brain injury, ${ }^{79}$ which results in damage to medullar respiratory control function..$^{35,80-84}$

It is extremely important to remark that the brainstem has been severely infected by SARS-CoV $\underline{34}, \underline{35}$ or MERS-CoV. It has been reported that viral antigens have been detected in the brainstem, where the infected regions included the nucleus of the solitary tract and nucleus ambiguous. Afferent axons from the carotid and aortic bodies in the 
glossopharyngeal nerve contain chemoreceptor cells, and vagal afferent nerves from receptors in the lung communicate with the medulla and pons respiratory control centers to coordinate inspiration and expiration, while the efferent fibers from the nucleus ambiguous and the nucleus of the solitary tract provide innervation to airway smooth muscle, glands, and blood vessels. Such neuroanatomic interconnections indicate that the death of infected animals or patients, due to respiratory distress, may be caused by dysfunction of the respiratory center in the brainstem. ${ }^{11,19,42,77,85,86}$

Based upon the first-hand evidence from Wuhan local hospitals, the common symptoms of COVID-19 were fever (83\%-99\%) and dry cough $(59.4 \%-82 \%)$ at the onset of illness. However, the most characteristic and deadly symptom of Covid-19 patients is respiratory distress. Among the patients with dyspnea, more than half needed mechanical respiratory support. About $46 \%$ to $65 \%$ of the patients in the intensive care worsened in a short period of time and died due to respiratory failure. ${ }^{87-90}$ Wang et al. reported that $11.1 \%$ received high-flow oxygen therapy, $41.7 \%$ received noninvasive ventilation, and $47.2 \%$ received invasive ventilation. These data suggest that most (about $89 \%$ ) of the patients in need of intensive care could not breathe spontaneously.

\section{Conclusion:}

With the recent COVID-19 outbreak, there is an urgent need to understand the neurotropic potential of the COVID-19 virus in order to prioritize and individualize the treatment protocols based on the severity of the disease and predominant organ involvement. $^{57}$

It also important to remark SARS-CoV-2 can invade the brainstem leading to respiratory center dysfunction. ${ }^{11,19,42,77,85,86}$ Hence, serial neurological examinations are 
recommended, with an exhaustive exploration of brainstem reflexes. As Neuroimaging techniques are not always easy to use in ventilated patients, ancillary tests, such as brainstem auditory and somatosensory evoked potentials, quantitative EEG, transcranial Doppler, can be used to monitor brain function in severe-acute Covid-19 patients.

Therefore, acute respiratory distress in Covid-19 can be partially explained by brainstem dysfunction, suggesting the needs of more specific and aggressive treatments with the direct participation of neurologists and neurointensivists.

Hence, in patients complaining Covid-19 admitted in ICUs due to acute respiratory failure, a brain complication should be considered for protocol treatments.

\section{REFERENCES}

1. Chatterjee P, Nagi N, Agarwal A, et al. The 2019 novel coronavirus disease (COVID-19) pandemic: A review of the current evidence. Indian J Med Res 2020.

2. Shah SGS, Farrow A. A commentary on "World Health Organization declares global emergency: A review of the 2019 novel Coronavirus (COVID-19)". Int J Surg 2020;76:128-129.

3. Ludwig S, Zarbock A. Coronaviruses and SARS-CoV-2: A Brief Overview. Anesth Analg 2020;doi:10.1213/ANE.0000000000004845.

4. Ahn DG, Shin HJ, Kim MH, et al. Current Status of Epidemiology, Diagnosis, Therapeutics, and Vaccines for Novel Coronavirus Disease 2019 (COVID-19). J Microbiol Biotechnol 2020;30:313-324.

5. Yang Y, Peng F, Wang R, et al. The deadly coronaviruses: The 2003 SARS pandemic and the 2020 novel coronavirus epidemic in China. J Autoimmun 2020;109:102434. 
6. de Lusignan S, Lopez Bernal J, Zambon M, et al. Emergence of a Novel Coronavirus (COVID-19): Protocol for Extending Surveillance Used by the Royal College of General Practitioners Research and Surveillance Centre and Public Health England. JMIR Public Health Surveill 2020;6:e18606.

7. Ghinai I, McPherson TD, Hunter JC, et al. First known person-to-person transmission of severe acute respiratory syndrome coronavirus 2 (SARS-CoV-2) in the USA. Lancet 2020;395:1137-1144.

8. Yang CY, Wang J. A mathematical model for the novel coronavirus epidemic in Wuhan, China. Math Biosci Eng 2020;17:2708-2724.

9. Baig AM. Neurological manifestations in COVID-19 caused by SARS-CoV-2. CNS Neurosci Ther 2020; doi: 10.1111/cns.13372

10. $\mathrm{Wu} \mathrm{Y,} \mathrm{Xu} \mathrm{X,} \mathrm{Chen} \mathrm{Z}$, et al. Nervous system involvement after infection with COVID-19 and other coronaviruses. Brain Behav Immun 2020; doi: 10.1016/j.bbi.2020.03.031.

11. Mao L, Jin H, Wang M, et al. Neurologic Manifestations of Hospitalized Patients With Coronavirus Disease 2019 in Wuhan, China. JAMA Neurol 2020: doi:10.1101/2020.02.22.20026500.

12. Pellegrino R, Han P, Reither N, Hummel T. Effectiveness of olfactory training on different severities of posttraumatic loss of smell. Laryngoscope 2019;129:17371743.

13. Zhou X, Huang F, Xu L, et al. Hepatitis E Virus Infects Neurons and Brains. J Infect Dis 2017;215:1197-1206.

14. Foley JE, Leutenegger C. A review of coronavirus infection in the central nervous system of cats and mice. J Vet Intern Med 2001;15:438-444. 
15. Talbot PJ, Ekande S, Cashman NR, Mounir S, Stewart JN. Neurotropism of human coronavirus 229E. Adv Exp Med Biol 1993;342:339-346.

16. Murray RS, Cai GY, Hoel K, Zhang JY, Soike KF, Cabirac GF. Coronavirus infects and causes demyelination in primate central nervous system. Virology $1992 ; 188: 274-284$.

17. Li Y, Bai WZ, Hashikawa T. Response to Commentary on: "The neuroinvasive potential of SARS-CoV-2 may play a role in the respiratory failure of COVID-19 patients". J Med Virol 2020;doi: 10.1002/jmv.25824.

18. Yan-Chao L, Whan Zhu B, Harshikawa T. The neuroinvasive potential of SARSCoV-2 may play a role in the respiratory failure of COVID-19 patients. Journal of Medical Virology 2020;doi: 10.1002/jmv.25728.

19. Li YC, Bai WZ, Hashikawa T. The neuroinvasive potential of SARS-CoV-2 may play a role in the respiratory failure of COVID-19 patients. J Med Virol 2020; doi:10.1002/jmv.25728.

20. Li Z, Huang Y, Guo X. The brain, another potential target organ, needs early protection from SARS-CoV-2 neuroinvasion. Sci China Life Sci 2020;doi: 10.1007/s11427-020-1690-y.

21. Rabaan AA, Al-Ahmed SH, Haque S, et al. SARS-CoV-2, SARS-CoV, and MERSCOV: A comparative overview. Infez Med 2020;28:174-184.

22. Gupta MK, Vemula S, Donde R, Gouda G, Behera L, Vadde R. In-silico approaches to detect inhibitors of the human severe acute respiratory syndrome coronavirus envelope protein ion channel. J Biomol Struct Dyn 2020:1-17.

23. Saghazadeh A, Rezaei N. Immune-epidemiological parameters of the novel coronavirus - a perspective. Expert Rev Clin Immunol 2020; doi:10.1080/1744666X.2020.1750954. 
24. Tresoldi I, Sangiuolo CF, Manzari V, Modesti A. SARS-COV-2 and infectivity. J Med Virol 2020;doi: 10.1002/jmv.25831.

25. Atkinson JR, Bergmann CC. Protective Humoral Immunity in the Central Nervous System Requires Peripheral CD19-Dependent Germinal Center Formation following Coronavirus Encephalomyelitis. J Virol 2017;91.

26. Lane TE, Hosking MP. The pathogenesis of murine coronavirus infection of the central nervous system. Crit Rev Immunol 2010;30:119-130.

27. Hirano N, Nomura R, Tawara T, Tohyama K. Neurotropism of swine haemagglutinating encephalomyelitis virus (coronavirus) in mice depending upon host age and route of infection. J Comp Pathol 2004;130:58-65.

28. Haring JS, Pewe LL, Perlman S. High-magnitude, virus-specific CD4 T-cell response in the central nervous system of coronavirus-infected mice. J Virol 2001;75:3043-3047.

29. Hein A, Schwender S, Imrich H, Sopper S, Czub M, Dorries R. Phenotypic and functional characterization of $\mathrm{CD} 8+\mathrm{T}$ lymphocytes from the central nervous system of rats with coronavirus JHM induced demyelinating encephalomyelitis. J Neurovirol 1995;1:340-348.

30. Yeh EA, Collins A, Cohen ME, Duffner PK, Faden H. Detection of coronavirus in the central nervous system of a child with acute disseminated encephalomyelitis. Pediatrics 2004;113:e73-76.

31. Andries K, Pensaert M. Propagation of hemagglutinating encephalomyelitis virus in porcine cell cultures. Zentralbl Veterinarmed B 1980;27:280-290.

32. Burke JF, Chan AK, Mummaneni V, et al. Letter: The Coronavirus Disease 2019 Global Pandemic: A Neurosurgical Treatment Algorithm. Neurosurgery 2020:doi: 10.1093/neuros/nyaa116. 
33. (WHO) TWHO. The First Few X (FFX) Cases and contact investigation protocol for 2019-novel coronavirus (2019-nCoV) infection. 29 January 2020 ed. Washington: The World Health Organization (WHO), 2020.

34. Arabi YM, Harthi A, Hussein J, et al. Severe neurologic syndrome associated with Middle East respiratory syndrome corona virus (MERS-CoV). Infection $2015 ; 43: 495-501$.

35. Machado C, Gutierrez JV. Anosmia and ageusia as initial or unique symptoms after sars-cov-2 virus infection (Review article). Preprints 2020, 2020040272 (doi: 10.20944/preprints202004.0272.v1).

36. Netland J, Meyerholz DK, Moore S, Cassell M, Perlman S. Severe acute respiratory syndrome coronavirus infection causes neuronal death in the absence of encephalitis in mice transgenic for human ACE2. J Virol 2008;82:7264-7275.

37. Xie M, Chen Q. Insight into 2019 novel coronavirus - an updated intrim review and lessons from SARS-CoV and MERS-CoV. Int J Infect Dis 2020;doi: 10.1016/j.ijid.2020.03.071.

38. Conde G, Quintana Pajaro LD, Quintero Marzola ID, Ramos Villega Y, Mascote Salazarb LT. Neurotropism of SARS-CoV 2: Mechanisms and manifestations. J Neurol Sci 2020;doi: 10.1016/j.jns.2020.116824.

39. Cheng J, Zhao Y, Xu G, et al. The S2 Subunit of QX-type Infectious Bronchitis Coronavirus Spike Protein Is an Essential Determinant of Neurotropism. Viruses $2019 ; 11$.

40. Bender SJ, Phillips JM, Scott EP, Weiss SR. Murine coronavirus receptors are differentially expressed in the central nervous system and play virus straindependent roles in neuronal spread. J Virol 2010;84:11030-11044. 
41. Arbour N, Cote G, Lachance C, Tardieu M, Cashman NR, Talbot PJ. Acute and persistent infection of human neural cell lines by human coronavirus OC43. J Virol $1999 ; 73: 3338-3350$.

42. Ceccarelli M, Berretta M, Venanzi Rullo E, Nunnari G, Cacopardo B. Differences and similarities between Severe Acute Respiratory Syndrome (SARS)CoronaVirus $(\mathrm{CoV})$ and SARS-CoV-2. Would a rose by another name smell as sweet? Eur Rev Med Pharmacol Sci 2020;24:2781-2783.

43. Hussain M, Jabeen N, Raza F, et al. Structural Variations in Human ACE2 may Influence its Binding with SARS-CoV-2 Spike Protein. J Med Virol 2020.

44. Dube M, Le Coupanec A, Wong AHM, Rini JM, Desforges M, Talbot PJ. Axonal Transport Enables Neuron-to-Neuron Propagation of Human Coronavirus OC43. J Virol 2018;92.

45. Levy LM, Degnan AJ, Sethi I, Henkin RI. Anatomic olfactory structural abnormalities in congenital smell loss: magnetic resonance imaging evaluation of olfactory bulb, groove, sulcal, and hippocampal morphology. J Comput Assist Tomogr 2013;37:650-657.

46. Rombaux P, Mouraux A, Bertrand B, Nicolas G, Duprez T, Hummel T. Retronasal and orthonasal olfactory function in relation to olfactory bulb volume in patients with posttraumatic loss of smell. Laryngoscope 2006;116:901-905.

47. Garcia-Cordovilla R, Fernandez-Soriano J, Garcia-Barrutia MS, Fernandez-Ruiz B. [Regions of the olfatory cortex in the telencephalon of the scalp Clemys caspica]. Trab Inst Cajal Invest Biol 1975;67:75-102.

48. Swanson PA, 2nd, McGavern DB. Viral diseases of the central nervous system. Curr Opin Virol 2015;11:44-54. 
49. Koyuncu OO, Hogue IB, Enquist LW. Virus infections in the nervous system. Cell Host Microbe 2013;13:379-393.

50. Jacomy H, St-Jean JR, Brison E, Marceau G, Desforges M, Talbot PJ. Mutations in the spike glycoprotein of human coronavirus OC43 modulate disease in BALB/c mice from encephalitis to flaccid paralysis and demyelination. J Neurovirol 2010;16:279-293.

51. St-Jean JR, Jacomy H, Desforges M, Vabret A, Freymuth F, Talbot PJ. Human respiratory coronavirus OC43: genetic stability and neuroinvasion. J Virol 2004;78:8824-8834.

52. Yan Y, Shin WI, Pang YX, et al. The First 75 Days of Novel Coronavirus (SARSCoV-2) Outbreak: Recent Advances, Prevention, and Treatment. Int J Environ Res Public Health 2020;17.

53. Sohrabi C, Alsafi Z, O'Neill N, et al. World Health Organization declares global emergency: A review of the 2019 novel coronavirus (COVID-19). Int J Surg 2020;76:71-76.

54. Asadi-Pooya AA, Yaghoubi E, Nikseresht A, Moghadami M, Honarvar B. The Neurological Manifestations of H1N1 Influenza Infection; Diagnostic Challenges and Recommendations. Iran J Med Sci 2011;36:36-39.

55. Li Y, Li H, Fan R, et al. Coronavirus Infections in the Central Nervous System and Respiratory Tract Show Distinct Features in Hospitalized Children. Intervirology 2016;59:163-169.

56. Bender SJ, Weiss SR. Pathogenesis of murine coronavirus in the central nervous system. J Neuroimmune Pharmacol 2010;5:336-354.

57. Nath A. Neurologic complications of coronavirus infections. Neurology 2020;94:12. 
58. Stoessl AJ, Bhatia KP, Merello M. Editorial: $M$ ovement disorders in the world of Covid-19. Mov Disord 2020;doi: 10.1002/mds.28069.

59. Papa SM, Brundin P, Fung VSC, et al. Impact of the COVID-19 pandemic on Parkinson's disease and movement disorders. Mov Disord 2020; doi: $10.1002 / \mathrm{mds} .28067$

60. Hung IF, Lau SK, Woo PC, Yuen KY. Viral loads in clinical specimens and SARS manifestations. Hong Kong Med J 2009;15 Suppl 9:20-22.

61. Rabi FA, Al Zoubi MS, Kasasbeh GA, Salameh DM, Al-Nasser AD. SARS-CoV2 and Coronavirus Disease 2019: What We Know So Far. Pathogens 2020;9.

62. Lau KK, Yu WC, Chu CM, Lau ST, Sheng B, Yuen KY. Possible central nervous system infection by SARS coronavirus. Emerg Infect Dis 2004;10:342-344.

63. Mao L, Wang M, Chen S, et al. Neurological Manifestations of Hospitalized Patients with COVID-19 in Wuhan, China: a retrospective case series study. MedRxiv 2020;doi: 10.1001/jamaneurol.2020.1127.

64. Chen $\mathrm{T}, \mathrm{Wu} \mathrm{D}$, Chen $\mathrm{H}$, et al. Clinical characteristics of 113 deceased patients with coronavirus disease 2019: retrospective study. BMJ 2020;368:m1091.

65. NHCotPsRo C. The guidelines for the diagnosis and treatment of novel coronavirus (2019-nCoV) infection (trial version 7) (in Chinese). 2020: http://www.nhc.gov.cn/yzygj/s7653p/202003/46c9294a7dfe4cef80dc7f5912eb198 9/files/ce3e6945832a438eaae415350a8ce964.pdf.

66. Okba NMA, Muller MA, Li W, et al. Severe Acute Respiratory Syndrome Coronavirus 2-Specific Antibody Responses in Coronavirus Disease 2019 Patients. Emerg Infect Dis 2020;26.

67. Wang JW, Cao B, Wang C. Science in the fight against the novel coronavirus disease. Chin Med J (Engl) 2020;doi: 10.1097/CM9.0000000000000777. 
68. Wang L, He W, Yu X, et al. Coronavirus Disease 2019 in elderly patients: characteristics and prognostic factors based on 4-week follow-up. J Infect 2020;doi: 10.1016/j.jinf.2020.03.019.

69. Cao Y, Liu X, Xiong L, Cai K. Imaging and Clinical Features of Patients With 2019 Novel Coronavirus SARS-CoV-2: A systematic review and meta-analysis. J Med Virol 2020: https://www.ncbi.nlm.nih.gov/pubmed/32242947.

70. Gattinoni L, Coppola S, Cressoni M, Busana M, Rossi S, Chiumello D. Covid-19 Does Not Lead to a "Typical" Acute Respiratory Distress Syndrome. Am J Respir Crit Care Med 2020;doi: 10.1164/rccm.202003-0817LE.

71. Zhou M, Zhang X, Qu J. Coronavirus disease 2019 (COVID-19): a clinical update. Front Med 2020;doi:10.1007/s11684-020-0767-8.

72. Huang C, Wang Y, Li X, et al. Clinical features of patients infected with 2019 novel coronavirus in Wuhan, China. Lancet 2020;395:497-506.

73. Wang J, Hajizadeh N, Moore EE, et al. Tissue Plasminogen Activator (tPA) Treatment for COVID-19 Associated Acute Respiratory Distress Syndrome (ARDS): A Case Series. J Thromb Haemost 2020;doi:10.1111/jth.14828.

74. Trujillo JA, Fleming EL, Perlman S. Transgenic CCL2 expression in the central nervous system results in a dysregulated immune response and enhanced lethality after coronavirus infection. J Virol 2013;87:2376-2389.

75. Rogers RC, Viard E, Hermann GE. CXCL12 sensitizes vago-vagal reflex neurons in the dorsal medulla. Brain Res 2013;1492:46-52.

76. Hermann GE, Van Meter MJ, Rogers RC. CXCR4 receptors in the dorsal medulla: implications for autonomic dysfunction. Eur J Neurosci 2008;27:855-864. 
77. Goehler LE, Gaykema RP, Opitz N, Reddaway R, Badr N, Lyte M. Activation in vagal afferents and central autonomic pathways: early responses to intestinal infection with Campylobacter jejuni. Brain Behav Immun 2005;19:334-344.

78. Fisher M, Smeiles C, Jnah AJ, Ruiz ME, Difiore T, Sewell K. Congenital Central Hypoventilation Syndrome: A Case-Based Learning Opportunity for Neonatal Clinicians. Neonatal Netw 2019;38:217-225.

79. Wienke A, Walter O. [Loss of the sense of taste and smell after head and brain injury]. Laryngorhinootologie 2001;80:752.

80. Estevez-Baez M, Machado C, Garcia-Sanchez B, et al. Autonomic impairment of patients in coma with different Glasgow coma score assessed with heart rate variability. Brain Inj 2019;33:496-516.

81. Estevez-Baez M, Carricarte-Naranjo C, Jas-Garcia JD, et al. Influence of Heart Rate, Age, and Gender on Heart Rate Variability in Adolescents and Young Adults. Adv Exp Med Biol 2019;1133:19-33.

82. Estevez-Baez M, Machado C, Montes-Brown J, et al. Very high frequency oscillations of heart rate variability in healthy humans and in patients with cardiovascular autonomic neuropathy. Adv Exp Med Biol 2018;1070:49-70.

83. Machado C, Estevez M, Perez-Nellar J, Schiavi A. Residual vasomotor activity assessed by heart rate variability in a brain-dead case. BMJ Case Rep 2015;2015.

84. Machado C, Estevez M, Rodriguez R, et al. Zolpidem arousing effect in persistent vegetative state patients: autonomic, EEG and behavioral assessment. Curr Pharm Des 2014;20:4185-4202.

85. Chang L, Zhao L, Gong H, Wang L, Wang L. Severe Acute Respiratory Syndrome Coronavirus 2 RNA Detected in Blood Donations. Emerg Infect Dis 2020;26. 
86. Matsuda $\mathrm{K}$, Park $\mathrm{CH}$, Sunden $\mathrm{Y}$, et al. The vagus nerve is one route of transneural invasion for intranasally inoculated influenza a virus in mice. Vet Pathol 2004;41:101-107.

87. Guan WJ, Ni ZY, Hu Y, et al. Clinical Characteristics of Coronavirus Disease 2019 in China. N Engl J Med 2020;doi:10.1056/NEJMoa2002032.

88. Matthay MA, Aldrich JM, Gotts JE. Treatment for severe acute respiratory distress syndrome from COVID-19. Lancet Respir Med 2020: 10.1016/S2213$2600(20) 30127-2$.

89. Ravikumar N, Nallasamy K, Bansal A, et al. Novel Coronavirus 2019 (2019-nCoV) Infection: Part I - Preparedness and Management in the Pediatric Intensive Care Unit in Resource-limited Settings. Indian Pediatr 2020: https://www.ncbi.nlm.nih.gov/pubmed/32238612.

90. Tang X, Du R, Wang R, et al. Comparison of Hospitalized Patients with Acute Respiratory Distress Syndrome Caused by COVID-19 and H1N1. Chest 2020; doi: 10.1016/j.chest.2020.03.032. 